\title{
Testicular and epididymal ultrasonography for the assessment of semen quality in the indigenous ram
}

\author{
Suchana Sarker ${ }^{1}$, Begum Fatema Zohara ${ }^{2}$, Azizunnesa $^{3}$, Md. Faruk Islam ${ }^{2}$ and \\ Farida Yeasmin Bari ${ }^{4, *}$ \\ ${ }^{1}$ Central Artificial Insemination laboratory, Savar, Dhaka 1341, Bangladesh \\ ${ }^{2}$ Department of Medicine, Surgery and Obstetrics, Hajee Mohammad Danesh Science and Technology University, \\ Dinajpur 5200, Bangladesh \\ ${ }^{3}$ Department of Medicine and Surgery, Chittagong Veterinary and Animal Science University, Chittagong 4225, \\ Bangladesh \\ ${ }^{4}$ Department of Surgery and Obstetrics, Bangladesh Agricultural University, Mymensingh 2202, Bangladesh
}

Received November 17, 2021

Revised November 26, 2021

Accepted November 26, 2021

\section{*Correspondence}

Farida Yeasmin Bari

E-mail: faridabari06@gmail.com

\section{Author's Position and Orcid no.}

Sarker S, Researcher as MS student, https://orcid.org/0000-0002-2986-8490

Zohara BF, Professor as Research supervisor, https://orcid.org/0000-0002-4101-5036 Azizunnesa, Professor as Researcher, https://orcid.org/0000-0002-5809-4164 Islam MF, Professor as Researcher, https://orcid.org/0000-0003-2331-0821 Bari FY, Professor as Research supervisor, https://orcid.org/0000-0003-1358-460X
ABSTRACT The aims of this study were to measure the ultrasonographic biometry of genitalia of the indigenous rams and observe the relationship of biometry on semen parameters. The epididymal volume was significantly reduced $(p<0.01)$ after semen collection compared with before collection for both left and right part in all rams. The cumulative results showed that although there was no significant difference in length, width and volume of epididymis between before and after semen collection, however the values were lower after collection. The epididymal length was significantly correlated with epididymal volume $(p<0.01)$, semen motility $(p<0.05)$ and semen morphology $(p<0.01)$. Epididymal width was only significantly correlated with epididymal volume $(p<0.01)$ not with the semen parameters. Epididymal volume had a significant correlation only with semen morphology $(p<0.01)$. The scrotal circumference had the significant correlation with semen density, mass activity, concentration and motility $(p<0.01)$. The epididymis had the similar or slightly increased echogenicity as compared to the normal testis. During whole study, some white spots were found on testis which did not affect the semen quantity and quality. Significant variation was observed only for semen concentration and motility among the rams $(p<0.05)$. The overall normal morphology was $90.5 \pm 4.6 \%$ with highest percentage of coiled tail abnormalities.

Keywords: epididymis, Ram, semen parameters, testis, ultrasonography

\section{INTRODUCTION}

Ram contributes half of the genetics to the flock and his success as a breeder will go a long way towards ensuring a profitable lamb crop (Zaher et al., 2020). Sheep rearing is gaining popularity in Bangladesh. Indiscriminate breeding, scarcity of superior rams and lack of scientific breeding program are the major constraints (Jha et al., 2020).Testicular size was ultimately correlated with capacity for sperm production, number of sperms ejaculated and sperm reservoirs (Palaszet et al., 1994). Testicular echotexture had a positive linear regression with daily sperm production and testicular tone had a negative linear regression with epididymal sperm reserves 
observed with ultra-sound scanning (Kastelic et al., 2001). In addition to seminal quality and scrotal circumference, testicular utrasonographic echotexture has considerable promise for augmenting breeding soundness examinations of bulls (Kastelic et al., 2001). Utrasonographic examination of the testes, epididymes and accessory sex glands has proven to be a valuable, noninvasive technique for the assessment of genital macroscopic morphology and pathology in several mammalian species of veterinary interest (Kähn, 2004) including the ram (Gouletsou et al., 2003). Though there is scarcity of breeding ram in Bangladesh, to increase and improve the sheep breeding, this circumstance needs the urgent necessity of preservation of ram semen. However, this preservation requires the quality semen. The literature on the relationship of biometry of genital tract before semen collection on quantity and quality measured by utrasonographic scanning is still limited in Bangladesh. Therefore the present study was conducted to observe the effects of biometry of ram geneitalia before semen collection on quality and quantity in the indigenous ram.

\section{MATERIALS AND METHOD}

The present study was conducted at the Department of Surgery and Obstetrics, Faculty of Veterinary Science, Bangladesh Agricultural University, Mymensingh from $\mathrm{Au}^{-}$ gust to November 2013.

\section{Animal selection and management}

Five adult ram of 24 to 30 months were selected. The Rams were maintained on natural grazing along with concentrate mixture (Maize grit, wheat bran, wheat polish with salt, at the rate of $0.5-1 \mathrm{~kg} / \mathrm{ram} /$ day).

\section{Utrasonographic study of ram genitalia}

The study was conducted at 10 am in every morning, approximately 10 days apart for a 6 visit during the whole experiment. It includes measurement of scrotal circumference, scanning of testicular and epididymal echotexture, measurement of length, width and volume of cauda epididymis before and after semen collection. The relationship of testicular and epididymal biometry before semen collection on its quality and quality was also observed.

\section{Measurement of scrotal circumference}

Scrotal circumference was measured before each time of semen collection. A gentle pressure was given at the base of the scrotum for apposition of the testis and scrotal circumference was measured by using a measuring tape. The data was recorded.

\section{Scanning of testicle and epididymis}

B-mode digital Ultrasound system (Vet Eickemeyer Magic 5000) with transrectal probe $5 \mathrm{MHz}$, (Probe type: C20615S), was used for utrasonographic scanning. The ultrasound monitor was placed at practical distance from rams on the table and the transducer face was lubricated with a suitable coupling medium (Eco Gel ${ }^{\mathrm{TM}}-250 \mathrm{mg}$, EcoMed Pharmaceutical Inc., Ontario, Canada). The testes and epididymis were grasped at the scrotal neck and the transducer was progressed cranially along the neck of the testis to the cauda epididymes. The ultrasound monitor and operator's eye were at comparable level for accurate reading of ultrasound images. The echotexture of testis and epididymis and length, width, volume of epididymis were measured and data were recorded on the sonographic screen before noted down.

\section{Detection of the diseases by ultrasonography}

Any abnormality on the testis and epididymes was observed by the pattern of echotexture; whether the sonographic image was homogenous or not.

\section{Semen assessment related to biometry of genital organ}

After sonographic scanning, semen was collected by Artificial Vagina (AV) Method. The sample was immediately transferred to the water bath at $37^{\circ} \mathrm{C}$ before evaluation. Then the semen was evaluated as Physical assessment and Microscopic assessment.

\section{Physical assessment}

Physical assessments included color, volume and density of collected semen form each ram. Volume was measured by the quantity on reading from graded collection tube. Color was measured by eye estimation. Density was also measured by eye estimation by slanting and up-righting the collection vial graded from 1 to 4 . Each datum was carefully measured and recorded. 


\section{Microscopic assessment}

Four parameters were used for the evaluation: (1) Mass activity (2) Individual motility, (3) Sperm morphology and (4) Sperm concentration. A drop $(0.5 \mu \mathrm{L})$ of semen was placed on a pre-warmed slide $\left(37^{\circ} \mathrm{C}\right)$ without any cover slip and examined under microscope equipped with phase-contrast optics (100X) to evaluate the mass activity. The mass activity was scored into 5 scales: $1=$ no motion, 2 = free spermatozoa moving without forming any waves, 3 = small, slow moving waves, $4=$ vigorous movement with moderately rapid waves and eddies and $5=$ dense, very rapidly moving waves and distinct eddies. For evaluating Individual motility, a drop $(0.5 \mu \mathrm{L})$ of semen diluted at 1:4 ratios with diluent was placed on a pre-warmed slide $\left(37^{\circ} \mathrm{C}\right)$ and covered with a cover slip. The motility was determined by eye-estimation of the proportion of spermatozoa moving progressively straight forward at higher magnification (400X). The morphology was observed at high magnification (1000X) A drop (0.5 $\mu \mathrm{L}$ ) of semen was fixed with $2 \mathrm{~mL}$ formol saline solution At least 100 spermatozoa were individually examined. The percentages of normal morphology were recorded. Semen samples and formol saline were always mixed at room temperature to prevent any temperature variationrelated damage to the spermatozoa. The concentration of spermatozoa (billion/mL) was determined by using hemocytometer (Herman and Madden, 1963). Semen samples were fixed and diluted with formol saline (1:400) to kill the spermatozoa. A drop of diluted semen was placed on the counting chamber from the edge of pipette and spermatozoa were allowed to settle for 5-6 minutes before placing the haemocytometer on the stage of the microscope. The spermatozoa were counted in 5 large squares, each containing 16 small squares. The large squares to be counted are four at corners and one in the middle of 25 large squares. The head of the spermatozoa in the large squares were counted and recorded. The concentration of spermatozoa per $\mathrm{mL}$ of semen was calculated by multiply- ing the total number of spermatozoa in 5 large squares by $2 \times 10^{7}$ (10 million).

\section{Data analysis}

Data were entered in Microsoft Excel worksheet, organized and processed for further analysis. Descriptive statistics were performed to calculated mean and standard deviations. SPSS Statistics 17.0 version was used for two tailed Pearson Correlation test and other analyses.

\section{RESULTS}

\section{Utrasonographic biometry of epididymes of indigenous ram}

The sonographic biometry of epididymis of indigenous ram is placed in Table 1 . The mean length of cauda epididymes of five rams was $19.5 \pm 1.1 \mathrm{~mm}, 18.4 \pm 0.5 \mathrm{~mm}$, $20.7 \pm 1.2 \mathrm{~mm}, 17.6 \pm 0.6 \mathrm{~mm}, 18.0 \pm 0.6 \mathrm{~mm}$, respectively. The overall mean was $19.3 \pm 2.3 \mathrm{~mm}$. The mean width of cauda epididymes was $17.6 \pm 0.3 \mathrm{~mm}, 18.2 \pm$ $0.3 \mathrm{~mm}, 17.9 \pm 0.8 \mathrm{~mm}, 17.8 \pm 0.8 \mathrm{~mm}, 16.8 \pm 0.8 \mathrm{~mm}$, respectively. The overall mean was $18.2 \pm 1.5 \mathrm{~mm}$. Mean epididymal volume of five rams was $3.5 \pm 0.3 \mathrm{~cm}^{3}, 3.5 \pm$ $0.3 \mathrm{~cm}^{3}, 3.8 \pm 0.3 \mathrm{~cm}^{3}, 3.1 \pm 0.4 \mathrm{~cm}^{3}, 3.1 \pm 0.4 \mathrm{~cm}^{3}$, respectively. The overall mean was $3.6 \pm 0.8 \mathrm{~cm}^{3}$.

\section{Comparison of sonographic biometry of epididymis before and after semen collection (individual and cumulative)}

The comparison of sonographic measurement of epididymis (individual ram and cumulative) before and after semen collection is shown in Table 2 and 3. The length of left epididymis was significantly higher in ram \#3 (21.3 \pm 2.8 ) compared with \# 1,2, 4 and 5. For the right epididymis, the significant difference in length was existed among all ram except ram\#5 (18.4 \pm 1.3$)$. The epididymal length was reduced in all or most of the rams after semen collection for both the sides. For epididymal width, there

Table 1. Biometry of Epididymis (Left + right) of indigenous ram (Mean \pm SD)

\begin{tabular}{lrrrrrr}
\hline \multirow{2}{*}{ Parameters } & \multicolumn{5}{c}{ Tag Number of Ram } \\
\cline { 2 - 7 } & \multicolumn{1}{c}{$\mathbf{1}$} & \multicolumn{1}{c}{$\mathbf{3}$} & $\mathbf{3}$ & $\mathbf{4}$ & $\mathbf{5}$ & Overall Mean \pm SD \\
\hline Epididymal Length $(\mathrm{mm})$ & $19.5 \pm 1.1$ & $18.4 \pm 0.5$ & $20.7 \pm 1.2$ & $17.6 \pm 0.6$ & $18.0 \pm 0.6$ & $19.3 \pm 2.3$ \\
Epididymal Width $(\mathrm{mm})$ & $17.6 \pm 0.3$ & $18.2 \pm 0.3$ & $17.9 \pm 0.8$ & $17.8 \pm 0.8$ & $16.8 \pm 0.8$ & $18.2 \pm 1.5$ \\
Epididymal Volume $\left(\mathrm{cm}^{3}\right)$ & $3.5 \pm 0.3$ & $3.5 \pm 0.3$ & $3.8 \pm 0.3$ & $3.1 \pm 0.4$ & $3.1 \pm 0.4$ & $3.6 \pm 0.8$ \\
\hline
\end{tabular}

Mean on the same row with different superscript differ significantly $(p<0.05)$. 
Sarker et al. Ultrasonography in the indigenous ram

Table 2. Comparison of sonographic biometry of epididymis before and after semen collection in individual ram

\begin{tabular}{|c|c|c|c|c|c|c|c|}
\hline \multirow{2}{*}{\multicolumn{2}{|c|}{ Parameters }} & \multicolumn{6}{|c|}{ Tag Number of Ram } \\
\hline & & 1 & 2 & 3 & 4 & 5 & Overall Mean \pm SD \\
\hline \multirow[t]{3}{*}{ Epididymal Length (mm) } & Left (Before) & $20.6 \pm 2.5$ & $18.9 \pm 1.8$ & $21.3 \pm 2.8^{\mathrm{a}}$ & $18.2 \pm 1.6^{b}$ & $18.5 \pm 2.8$ & $19.3 \pm 2.3$ \\
\hline & Right (Before) & $20.3 \pm 1.7^{\text {ca }}$ & $18.7 \pm 2.4^{\mathrm{bc}}$ & $22.1 \pm 2.0^{\mathrm{a}}$ & $18.0 \pm 2.0^{\mathrm{da}}$ & $18.4 \pm 1.3^{\mathrm{ce}}$ & \\
\hline & Right (After) & $18.8 \pm 1.1$ & $17.9 \pm 2.8$ & $19.9 \pm 1.2^{\mathrm{a}}$ & $17.3 \pm 1.9^{b}$ & $18.1 \pm 1.7$ & \\
\hline & Right (Before) & $17.8 \pm 1.5$ & $18.52 \pm 1.8$ & $18.9 \pm 1.8$ & $18.7 \pm 1.5$ & $17.5 \pm 0.9$ & \\
\hline & Right (After) & $17.4 \pm 1.8$ & $18.2 \pm 1.8^{\mathrm{a}}$ & $17.7 \pm 2.0$ & $17.9 \pm 1.7$ & $16.3 \pm 1.3^{b}$ & \\
\hline \multirow[t]{3}{*}{ Epididymal Volume $\left(\mathrm{cm}^{3}\right)$} & Left (Before) & $3.7 \pm 0.6$ & $3.6 \pm 0.9$ & $3.9 \pm 0.6$ & $3.3 \pm 0.8$ & $3.5 \pm 0.4$ & $3.6 \pm 0.8$ \\
\hline & Left (After) & $3.1 \pm 0.4$ & $3.2 \pm 0.7$ & $3.5 \pm 0.6^{a}$ & $2.57 \pm 0.9^{c}$ & $2.6 \pm 0.7^{b c}$ & \\
\hline & Right (Before) & $3.7 \pm 0.3$ & $3.8 \pm 1.0$ & $4.1 \pm 1.0$ & $3.5 \pm 1.0$ & $3.4 \pm 1.0$ & \\
\hline
\end{tabular}

Mean on the same row with different superscript differ significantly $(p<0.05)$.

Table 3. Ultrasonographic biometry of epididymis (Left and Right) before and after semen collection in the indigenous ram (Pulled over)

\begin{tabular}{lccc}
\hline \multicolumn{1}{c}{ Parameters } & Befere collection & After Collection & N \\
\hline Epididymal Length $(\mathrm{mm})$ & $18.9 \pm 2.2$ & $18.7 \pm 2.3$ & Not significant \\
Epididymal Width $(\mathrm{mm})$ & $17.9 \pm 1.6$ & $17.5 \pm 1.7$ & Not significant \\
Epididymal Volume $\left(\mathrm{cm}^{3}\right)$ & $3.4 \pm 0.7$ & $3.3 \pm 0.9$ & Not significant \\
\hline
\end{tabular}

Table 4. Correlation of epididymal biometry and scrotal circumference with semen parameters in the indigenous rams

\begin{tabular}{lcccccccc}
\hline \multicolumn{1}{c}{ Parameters } & EV & SV & SD & SMA & SC & SM & ScC & SMor \\
\hline Epididymal Length & $.731^{* *}$ & -.181 & .101 & -.063 & -.054 & $.312^{*}$ & .061 & $.336^{* *}$ \\
Epididymal Width & $.568^{* *}$ & .091 & .070 & -.094 & -.102 & -.184 & -.010 & .244 \\
Epididymal Volume & - & -.237 & .062 & -.180 & .003 & .191 & -.022 & $.427^{* *}$ \\
Scrotal Circumference & -.022 & .086 & $.424^{* *}$ & $.447^{* *}$ & $.590^{* *}$ & $.413^{* *}$ & - & .239 \\
\hline
\end{tabular}

${ }^{*} p<0.05,{ }^{* *} p<0.01$.

EV, Epididymal Volume; SV, Semen Volume; SD, Semen Density; SMA, Semen Mass Activity; SC, Semen Concentration; SM, Semen Motility; ScC, Scrotal Circumference; SMor, Semen Morphology.

was no difference in left and right epididymis among the rams for both before and after semen collection except 2 and ram\#5 $(p<0.05 ; 18.2 \pm 1.8$ and $16.3 \pm 1.3)$. In most of the rams, the width was reduced after semen collection compared with before collection. For epididymal volume, there was no significant difference among the ram for both before and after semen collection except ram\#3, 4 and 5 ( $p$ $<0.05 ; 3.5 \pm 0.6,2.57 \pm 0.9$ and $2.6 \pm 0.7)$. However, the volume was significantly reduced $(p<0.01)$ after semen collection compared with before collection for both left and right part in all rams. The cumulative results (Table 3) showed that although there was no significant difference in length, width and volume of epididymis between before and after semen collection $(p<0.05 ; 18.9 \pm 2.2$ vs. $18.7 \pm$ $2.3,17.9 \pm 1.6$ vs. $17.5 \pm 1.7$ and $3.4 \pm 0.7$ vs. $3.3 \pm 0.9)$ however the values were lower after collection.

\section{Correlations between testicular and epididymal biometry and semen parameters in the indigenous ram}

The correlation between epididymal biometry and semen parameters is placed in Table 4. The epididymal length was significantly correlated with epididymal volume $(p<.01)$, semen motility $(p<0.05)$ and semen morphology $(p<0.01)$. Epididymal width was only significantly correlated with epididymal volume $(p<0.01)$ not with the semen parame- 
ters. Epididymal volume had a significant correlation only with semen morphology $(p<0.01)$. The scrotal circumference of indigenous rams varied from $21.3 \mathrm{~cm}$ to $24.1 \mathrm{~cm}$. The mean circumference was scrotal circumference of five individual animals was $23.6 \pm 0.9 \mathrm{~cm}, 22.5 \pm 0.6 \mathrm{~cm}$, $22.2 \pm 1.7 \mathrm{~cm}, 23.0 \pm 0.6 \mathrm{~cm}, 21.6 \pm 0.2 \mathrm{~cm}$, respectively and the overall mean was $22.3 \pm 1.2 \mathrm{~cm}$. The scrotal circumference had the significant correlation with semen density, mass activity, concentration and motility $(p<0.01)$.

\section{Utrasonographic scanning for echo-texture of testis and epididymis of indigenous ram}

With gray-scale equipment, the normal testis appeared as an oval structure with a fairly homogenous mediumgray to dark-gray internal echo pattern (Fig. 1). The borders of the testis were well circumscribed and distinguishable from the surrounding structures.

The epididymis had the similar or slightly increased echogenicity as compared to the normal testis (Fig. 1). Before semen collection the image was darker due to sperm accumulation than after semen collection. During
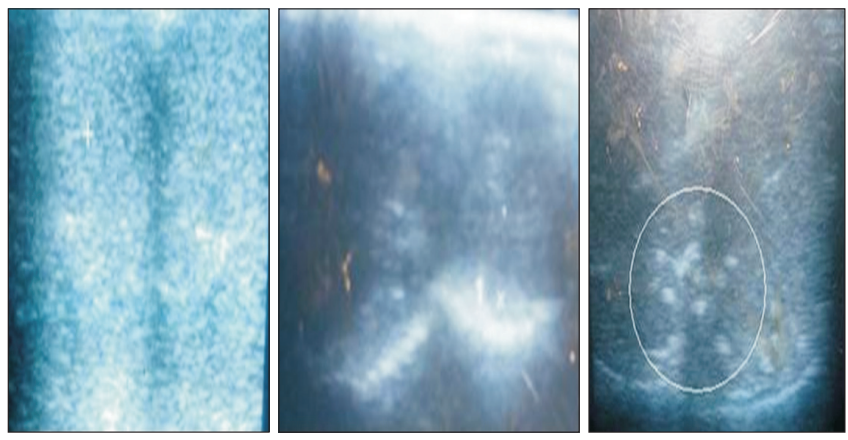

Fig. 1. Ultrasonographic image of testis, epididymes and white spots on the testis of ram. whole study, some white spots were found on testis in ram \#5 (Fig. 1). However it did not affect the semen quality and quantity.

\section{Semen characteristics of indigenous rams}

The semen characteristics of indigenous rams are shown in Table 5. The color of semen varied from milky to creamy. The volume varied from 0.8 to $1.7 \mathrm{~mL}$. The mean volume was $1.5 \pm 0.3 \mathrm{~mL}, 1.4 \pm 0.3 \mathrm{~mL}, 1.5 \pm 0.3 \mathrm{~mL}, 1.3$ $\pm 0.3 \mathrm{~mL}, 1.3 \pm 0.4 \mathrm{~mL}$, respectively and overall mean was $1.3 \pm .3 \mathrm{~mL}$. Average density of semen of five rams was $2.8 \pm 0.4,3 \pm 0,2.9 \pm 0.4,3 \pm 0,2.8 \pm 0.4$, respectively and the overall mean density was $2.8 \pm 0.4$ (in the scale of 4 ). The mass activity varied from 3 to 5 during the period of experiment. Average mass activity was $4.4 \pm$ $0.9,4.6 \pm 0.6,4.2 \pm 0.8,4.2 \pm 0.5,4 \pm 0.7$, respectively and overall mean was $4.1 \pm 0.6$ (in the scale of 5). Individual motility of five animals varied from 70 to $90 \%$. The average individual motility was $87 \pm 4.5,83 \pm 0.0,83 \pm$ $0.1,82 \pm 0.0,77 \pm 0.1 \%$, respectively and overall mean was $82.0 \pm 6.7 \%$. Significant variation was observed only for semen concentration and motility among the rams ( $p$ $<0.05$ ). The number of abnormal sperm varied from 2 to 14 cells (in 100 sperm cells). The average of morphologically normal spermatozoa was $90.2 \pm 4.0,91.5 \pm 3.4$, $92 \pm 4.0,90.7 \pm 4.2,91.7 \pm 4.5 \%$, respectively and the overall mean was $90.5 \pm 4.6 \%$. Coiled tail, bent tail, pearshaped head, pyriform shaped head, split tail, loose head, narrow head were found in the formol saline fixed slide. Among the abnormalities observed coiled tail was the highest percentages.

Table 5. Semen characteristics of indigenous rams

\begin{tabular}{lcccccc}
\hline \multirow{2}{*}{ Parameters } & \multicolumn{5}{c}{ Tag Number of Ram } \\
\cline { 2 - 6 } & $\mathbf{1}$ & $\mathbf{2}$ & $\mathbf{3}$ & $\mathbf{4}$ & $\mathbf{5}$ & Overall Mean \pm SD \\
\hline Semen Volume (mL) & $1.5 \pm 0.3$ & $1.4 \pm 0.3$ & $1.5 \pm 0.3$ & $1.3 \pm 0.3$ & $1.3 \pm 0.4$ & $1.3 \pm 0.3$ \\
Semen Density (scale 4) & $2.8 \pm 0.4$ & $3.0 \pm 0$ & $2.9 \pm 0.4$ & $3.0 \pm 0$ & $2.8 \pm 0.4$ & $2.8 \pm 0.4$ \\
Semen Mass Activity (scale 5) & $4.4 \pm 0.9$ & $4.6 \pm 0.6$ & $4.2 \pm 0.8$ & $4.2 \pm 0.5$ & $4.0 \pm 0.7$ & $4.1 \pm 0.6$ \\
Semen morphology & $90.2 \pm 4.0$ & $91.5 \pm 3.4$ & $92 \pm 4.0$ & $90.7 \pm 4.2$ & $91.7 \pm 4.5$ & $90.5 \pm 4.6$ \\
Semen Concentration (million) & $216 \pm 27.1^{\mathrm{b}}$ & $206.6 \pm 9.8$ & $192.1 \pm 38.4^{\mathrm{c}}$ & $219.3 \pm 26.5^{\mathrm{ab}}$ & $208.0 \pm 30.0$ & $202.0 \pm 32.6$ \\
Semen Motility (\%) & $87 \% \pm 4.5^{\mathrm{a}}$ & $83 \% \pm 0.0$ & $83 \% \pm 0.1$ & $82 \% \pm 0.0$ & $77 \% \pm 0.1^{\mathrm{b}}$ & $82.0 \pm 6.7$ \\
Scrotal Circumference (cm) & $23.6 \pm 0.9^{\mathrm{a}}$ & $22.5 \pm 0.6$ & $22.2 \pm 1.7^{c}$ & $23.0 \pm 0.6^{\mathrm{bac}}$ & $21.6 \pm 0.2^{\mathrm{d}}$ & $22.3 \pm 1.2$ \\
\hline
\end{tabular}

Mean on the same row with different superscript differ significantly $(p<0.05)$. 


\section{DISCUSSION}

It is important to preserve the quality semen which requires the assessment before collection, giving the importance of the observation of positive correlation of biometry of ram genitalia with semen parameters for selection of rams. Utrasonographic examination of the testes, epididymes and accessory sex glands has proven to be a valuable, noninvasive technique for the assessment of genital macroscopic morphology and pathology in several mammalian species of veterinary interest (Kähn, 2004) including the ram (Gouletsou et al., 2003). Ahmad et al., (1991) reported the ultsonographic appearance of infertile goats with testicular degeneration.

The biometry of sheep genitalia have been done by many authors by gross study (Ibrahim et al., 2012). However, there is no observable published literature on the utrasonographic biometry measurement of genitalia of ram (if any). Establishment of this type of study will reduce problems of gross measurement involving the hazards for slaughter house sample collection, reducing the time and labor cost for measurement. This is an interesting study with the advance of science at the present study using the ultrasonography machine for improving and increasing the livestock animals. This will facilitate the treatment and management of reproductive diseases and disorders. This may also facilitates quality ram semen preservation by selecting the high quality rams through quickly correlating the biometry with semen parameters.

The overall mean scrotal circumference was $22.3 \pm 1.2 \mathrm{~cm}$. It is quite lower than the previously published result (10). This might be for the Variation in age, breed, bodyweight, season and nutrition. The scrotal circumference had the significant correlation with semen density, mass activity, concentration and motility $(p<0.01)$. Other established literature also found on this work (Palaszet et al., 1994; Kastelic et al., 2001; Tatsunami et al., 2006).

Testicular ultrasonography has been a generally rewarding procedure because of its simplicity in delineating testicular and paratesticular architecture, and because of its noninvasiveness. With gray-scale equipment, the normal testis appeared as an oval structure with a fairly homogenous medium-gray to dark-gray internal echo pattern. The borders of the testis were well circumscribed and distinguishable from the surrounding structures. The epididymis had the similar or slightly increased echogenicity as compared to the normal testis. Before semen collection the image was darker due to sperm accumulation than after semen collection. The utrasonographic appearance of the testis and other reproductive organs is described in bulls (Cartee et al., 1989; Pugh et al., 1990), dogs (Pugh et al., 1990) and goats and rams (Ahmad et al., 1991). The echotexture, or the utrasonographic appearance of a tissue, can be assessed by determining the pixel intensity and uniformity (Liu et al., 2008). Testicular echotexture had a positive linear regression with daily sperm production and testicular tone had a negative linear regression $(p<0.008)$ with epididymal sperm reserves observed with ultra-sound scanning (Kastelic et al., 2001). During whole study, the testicular ultrasonography showed some focal areas with white spots indicating chronic inflammation with calcification (2-5) in one ram. However it did not affect the semen quantity and quality.

The color of semen varied from milky to creamy. The volume varied from 0.8 to $1.7 \mathrm{~mL}$. The mean volume was $1.5 \pm 0.3 \mathrm{~mL}, 1.4 \pm 0.3 \mathrm{~mL}, 1.5 \pm 0.3 \mathrm{~mL}, 1.3 \pm 0.3 \mathrm{~mL}$, $1.3 \pm 0.4 \mathrm{~mL}$, respectively and overall mean was $1.3 \pm .3$ $\mathrm{mL}$. In other published study, the average volume of ram semen varied from 0.8-1.1 $\pm 0.1 \mathrm{~mL}$ (Guerrero et al., 2009; Pervage et al., 2009; Kulaksiz et al., 2012). The semen volume is little higher than the past published works. This could be for the variation in age, breed, season and nutritional status.

Semen density has a significant correlation with semen concentration $(p<0.01)$, scrotal circumference $(p<0.01)$ and semen morphology $(p<0.05)$ in present study. Present result is nearer to the published literature (Gergátz, 2007). Mass activity of fresh semen is an indicator of the quality of motility of preserved semen. The mass activity varied from 3 to 5 during the period of experiment. Average mass activity was $4.4 \pm 0.9,4.6 \pm 0.6,4.2 \pm 0.8,4.2 \pm$ $0.5,4 \pm 0.7$, respectively and overall means was $4.1 \pm 0.6$, which is relevant with the result of other published work within the same breed (Pervage et al., 2009).

Individual motility of five animals varied from 70 to $90 \%$. The average individual motility was $87.0 \pm 4.5$, $83.0 \pm 0.0,83.0 \pm 0.1,82.0 \pm 0.0,77.0 \pm 0.1 \%$, respectively and overall mean was $82.0 \pm 6.7 \%$. This result is little lower than the results were published (Guerrero et al., 2009; Pervage et al., 2009; Kulaksiz et al., 2012). The variation may occur for the difference in age, breed and season. Significant variation was observed only for semen 
concentration and motility among the rams $(p<0.05)$. The number of abnormal sperm varied from 2 to 14 cells (in 100 sperm cells). The average of morphologically normal spermatozoa was $90.2 \pm 4.0,91.5 \pm 3.4,92.0 \pm 4.0$, $90.7 \pm 4.2$, $91.7 \pm 4.5 \%$, respectively and the overall mean was $90.5 \pm 4.6 \%$. Guerrero et al. (2009) found live sperm $90.2 \pm 3.8 \%$, which was similar to the present study. Coiled tail, bent tail, pear-shaped head, pyriform shaped head, split tail, loose head, narrow head were found in the formol saline fixed slide. Among the abnormalities observed coiled tail was the highest percentages. Large numbers of spermatozoa with abnormal tails were associated with reduced sperm motility (Söderquist, 1991). In the present study the average sperm concentration was $202.0 \pm 32.6$ million. In other studies, the concentration was $2.4 \times 10^{9}-$ $4.3 \times 10^{9}(16), \geq 2.5 \times 10^{9}$ spermatozoa/mL (Kulaksiz et al., 2012). The result is little lower than the previous study due to the factors stated before.

The epididymal length before semen collection may affect the semen motility and morphology. However, the epididymal volume may affect the semen morphology. The scrotal circumference may significantly correlate with semen density, mass activity, concentration and motility. Ultrasonographic scanning shows the oval structure of the normal testis with a fairly homogenous medium-gray to dark-gray internal echo pattern. The borders of the testis are well circumscribed and distinguishable from the surrounding structures. The epididymis may be similar or slightly increased in echogenicity as compared to the normal testis. Before semen collection the image may darker due to sperm accumulation than after semen collection.

\section{CONCLUSION}

The overall mean semen volume, density, mass activity, morphology, concentration, motility of semen was $1.3 \pm 0.3 \mathrm{~mL}, 2.8 \pm 0.4,4.1 \pm .6,90.5 \pm 4.6 \%, 202.0 \pm$ 32.6 million and $82.0 \pm 6.7 \%$, respectively. Significant variation may exist for semen concentration and motility among the rams. Epididymal volume had a significant correlation only with semen morphology. The scrotal circumference had the significant correlation with semen density, mass activity, concentration and motility. The epididymis had slightly increased echogenicity as compared to the normal testis. Only 5 rams were used in the present study. Among them only one ram had the abnormal echotexture. Therefore, further study involving large numbers of rams are needed to establish the present conclusions.

Author Contributions: Conceptualization, S.S., B.F.Z., F.Y.B.; data curation, software and formal analysis, S.S., B.F.Z., M.F.I.; methodology, S.S., B.F.Z., A., M.F.I., and F.Y.B.; writing original draft, S.S.; writing - Review and editing, B.F.Z. and F.Y.B.

Funding: This research work was generated from one my research project funded by Bangladesh Academy of Science and USDA (BAS-USDA).

Ethical Approval: This research work was conducted by the monitoring of Bangladesh Agricultural University Research System (BAURES) who are responsible for the coordination and management of all research projects of this University. Ethical approval was also given by BAURES.

\section{Consent to Participate: Yes.}

Consent to Publish: Yes.

\section{Availability of Data and Materials: Yes.}

Acknowledgements: The authors are grateful to Bangladesh Academy of Science (BAS-USDA) and Department of Surgery and Obstetrics, Bangladesh Agricultural University, Mymensingh-2202 for financial and logistic support of this study.

Conflicts of Interest: No potential conflict of interest relevant to this article was reported.

\section{REFERENCES}

Ahmad N, Noakes DE, Subandrio AL. 1991. B-mode real time ultrasonographic imaging of the testis and epididymis of sheep and goats. Vet. Rec. 128:491-496.

Cartee RE, Gray BW, Powe TA, Hudson RS, Whitesides J. 1989. Preliminary implications of B-mode ultrasonography of the testicles of beef bulls with normal breeding soundness examinations. Theriogenology 31:1149-1157.

Gergátz E. 2007. [Artificial insemination of sheep]. In: Pécsi T (Ed.), [Artificial Insemination of Domestic Mammals], Mezőgazda Press, Budapest, pp. 335-367. Hungarian.

Gouletsou PG, Amiridis GS, Cripps PJ, Lainas T, Deligiannis K, 
Saratsis P, Fthenakis GC. 2003. Ultrasonographic appearance of clinically healthy testicles and epididymides of rams. Theriogenology 59:1959-1972.

Guerrero VH, Huanca LW, Raymundo TF, Huerta OS, Ramos D. 2009. [Hypertonic extenders in the cryopreservation of ovine semen]. Rev. Investig. Vet. Peru 20:41-46. Spanish.

Herman HA and Madden FW. 1963. The Artificial Insemination of Dairy and Beef Cattle: A Handbook and Laboratory Manual. Lucas Brothers, Columbia, pp. 579-610.

Ibrahim AA, Aliyu J, Ashiru M, Jamilu M. 2012. Biometric study of the reproductive organs of three breeds of sheep in Nigeria. Int. J. Morphol. 30:1597-1603.

Jha PK, Alam MGS, Al Mansur MA, Talukder MRI, Naher N, Rahman AKMA, Hall DC, Bari FY. 2020. Effects of number of frozen-thawed ram sperm and number of inseminations on fertility in synchronized ewes under field condition. J. Anim. Reprod. Biotechnol. 35:190-197.

Kastelic JP, Cook RB, Pierson RA, Coulter GH. 2001. Relationships among scrotal and testicular characteristics, sperm production, and seminal quality in 129 beef bulls. Can. J. Vet. Res. 65:111-115.

Kulaksiz R, Çebi Ç, Akçay E. 2012. The effect of different extenders on the motility and morphology of ram sperm frozen or stored at $4{ }^{\circ} \mathrm{C}$. Turk. J. Vet. Anim. Sci. 36:177-182.

Kähn W. 2004. Veterinary Reproductive Ultrasonography: Horse, Cattle, Sheep, Goat, Pig, Dog, Cat. Schlütersche,
Hannover, pp. 256.

Liu X, Hart EJ, Petrik JJ, Nykamp SG, Bartlewski PM. 2008. Relationships between ultrasonographic image attributes, histomorphology and proliferating cell nuclear antigen expression of bovine antral follicles and corpora lutea ex situ. Reprod. Domest. Anim. 43:27-34.

Palasz AT, Cates WF, Barth AD, Mapletoft RJ. 1994. The relationship between scrotal circumference and quantitative testicular traits in yearling beef bulls. Theriogenology 42:715726.

Pervage S, Hassan MR, Ershaduzzaman M, Khandoker MAMY. 2009. Preservation of liquid semen and artificial insemination in native sheep. J. Bangladesh Agric. Univ. 7:305-308.

Pugh CR, Konde LJ, Park RD. 1990. Testicular ultrasound in the normal dog. Vet. Radiol. 31:195-199.

Söderquist L. 1991. Sperm characteristics and fertility in dairy AI bull. Phd thesis, Swedish University of Agricultural Sciences.

Tatsunami S, Matsumiya K, Tsujimura A, Itoh N, Sasao T, Koh E, Maeda Y, Eguchi J, Takehara K, Nishida T, Miyano S, Tabata C, Iwamoto T. 2006. Inter/intra investigator variation in orchidometric measurements of testicular volume by ten investigators from five institutions. Asian J. Androl. 8:373-378.

Zaher HA, Alawaash SA, Swelum AA. 2020. Effects of season and breed on the reproductive performance of sheep. J. Anim. Reprod. Biotechnol. 35:149-154. 